\title{
Development and Application of Spatially Parameterized Depth Duration Frequency Model for Estimation of Design Rainfall for Oromia State, Ethiopia
}

\author{
Megersa Tesfaye $^{1^{*}}$ and Solomon Seyoum Demissie ${ }^{2}$ \\ ${ }^{1}$ Department of Hydraulic and Water Resources Engineering, College of Engineering and Technology, \\ Post Box No: 395, Wollega University, Nekemte, Ethiopia \\ ${ }^{2}$ Ethiopian Institute of Water Resources, Akaki Campus, Post Box No: 150461, Addis Ababa, Ethiopia
}

\begin{abstract}
The magnitude and frequency of extreme rainfall events are required for planning, design and operation of many hydrological and water resources projects. Design rainfall depth is often used to estimate the severity and rarity of floods in areas where flow records are not sufficient enough to warrant direct flood estimation. The design of hydraulic structures on un-gauged streams and creeks, such as bridges, culverts, spillways, water harvesting and flood defense mechanisms depends upon proper estimation of extreme rainfall events. Quantification of design rainfall is generally done by using information contained in Depth-Duration-Frequency (DDF) relationships. Depth Duration Frequency relationships are currently constructed based on at site frequency analysis of rainfall data separately for different durations. These relationships are not accurate and reliable since they depend on assumptions such as distribution selection for each duration; they require a large number of parameters, experience intensive equations and regionalization is also very poor and coarse. In this study a DDF model with gridded set of parameters is developed for estimation of point rainfall frequencies for a range of duration for any location in Oromia regional state. A DDF model was fitted to series of annual maxima and its parameters were determined by a least squares method and these parameters were interpolated and mapped on a $1 \mathrm{~km}$ grid. The model allows for a parsimonious and efficient parameterization of DDF relationships, and its performance is shown to improve the reliability and robustness of design storm predictions as compared with those achievable by interpolating the quantile predictions of extreme rainfall data for specific durations. Moreover, design rainfall estimates found from the scaling DDF model are comparable to estimates obtained from traditional techniques; however, the scaled approach was more efficient and gives more reliable estimate compared with the observed rainfall depth at all stations.
\end{abstract}

Article Information Article History:

Received : 02-10-2014

Revised : 17-12-2014

Accepted : 26-12-2014

Keywords:

Scaling Properties

Depth Duration Frequency

Oromia Regional State

Ethiopia

Rainfall Depth Series

Frequency relationships

Hydrologic cycle

${ }^{*}$ Corresponding Author:

Megersa Tesfaye

E-mail:

megersatesfaye@gmail.com

\section{INTRODUCTION}

Since rainfall is an integral component in the hydrologic cycle, engineers must be able to quantify rainfall in order to design structures impacted with or dealing with the collection, conveyance, and storage of excess water. Quantification of rainfall is generally done by using information contained in Depth-DurationFrequency relationships. Depth-Duration-Frequency relationship is an essential tool used by engineers for planning, design and management of safe and cost efficient hydro-system infrastructures for certain amount of risk that the capacity may be exceeded. Depth-DurationFrequency relationship of precipitation can be defined as the amount of precipitation accumulated over a time period and how often that amount is recorded. Tortoreli et al. (1998) explained that the Depth-Duration-Frequency relationship of precipitation is taken in to account in the design of drainage structures for storm drains or roadways, parking lots and culverts. Depth-Duration-
Frequency information is also useful for rainfall-runoff models whose information is crucial for designing safe structures in flood prone areas. This paper focuses on the development of rainfall Depth-Duration-Frequency relationship for Oromia regional state with gridded set of parameter values summarizing the relationship, and there by enable the production of consistent estimates of point rainfall frequencies over duration of interest. For this purpose the hourly rainfall depth series from fifty five stations in the study region were collected and analyzed. Statistical parameters and properties of time scale invariance of rainfall are examined. Then, a model summarizing Depth-Duration-Frequency relationship of extreme rainfall depth series with gridded set of parameters which allows for the estimation of point design rainfall frequencies for a range of duration for any location within the region were developed. 
Megersa Tesfaye and Solomon Seyoum

\section{MATERIALS AND METHODS}

The materials used for this research were, Hourly extreme rainfall depth series, Arch GIS software, Spreadsheet/MS Excel 2007 for data analysis and Surfer software

\section{Methodology}

Fifty five first-class automatic recording stations with sufficient length of record and believed to represent different climatic characteristics within the region were selected to retrieve rainfall depth from available charts. These include forty-seven stations located within the Oromia regional state and eight stations were added from peripheral regions. (i.e. SNNPRS, Amahara, BenshangulGumze, Afar, and Somalia regions). From the data base of these first class stations with automatic rainfall recording gauges, annual maximum rainfall values for $0.5 \mathrm{hr}, 1 \mathrm{hr}, 2 \mathrm{hr}, 3 \mathrm{hr}, 5 \mathrm{hr}, 6 \mathrm{hr}, 12 \mathrm{hr}$, and $24 \mathrm{hr}$ having a record of 30 years(1980-2012) were collected by applying fixed duration data collection technique. The stations are assumed to be representative of different climatic regions. Rainfall frequency analysis assumes that the statistical estimation of extreme rainfall value is established on the assumption that the extreme rainfall data samples are homogeneous, stationary, independent and identically distributed. In other words, any systematic change in the statistical properties of the extreme rainfall events would not exist through time and the extreme rainfall data samples are not significantly auto-correlated. Owing to this all the collected data series for all stations were checked for consistency, using double mass curve method. The data were also tested for independence and stationarity by a fortran programme based on lag-one serial correlation coefficient test and Wald-Wolfowitz (WW) respectively.

Statistical analysis based on product moments and probability weighted moments was employed to summarize the extreme rainfall data series and to investigate the scaling properties of extreme rainfall depth series in the study region. Based on the scale invariance and the assumption of the power law dependence of all statistical moments on the scale of aggregation, a scaling DDF model that best robustly explains the rainfall depth duration frequency relationships with gridded set of parameters in the region was developed. The model was fitted to series of annual maxima and the parameters of the model were estimated by least square method, and these were also interpolated and mapped on $1 \mathrm{~km}$ grid by ordinary kriging. The model was applied in the study region and its efficiency was tested against quantile
Sci. Technol. Arts Res. J., Oct-Dec 2014, 3(4): 143-151

estimate from logEV1 distribution, observed hourly rainfall depth and empirical IDF estimates previously developed for the region.

\section{RESULTS AND DISCUSSION Model Development}

For many hydrological analyses, planning or design problems, reliable rainfall depth (intensity) estimates are necessary. Rainfall depth duration frequency relationship comprises of the estimate of rainfall depth at different durations and recurrence intervals. The rainfall fields exhibits a high temporal variability which generates a large degree of uncertainty in modeling the process, thus causing lack of accuracy in many key hydrological problems such as the forecasting of flood and the management of water resources. The large amount of literature produced in the last three decades about this issue, deals with the development of stochastic models able to represent non-linearity and intermittence of rainfall observed or forecasted at large scales. Traditionally, these models are based on point processes based on both the time (Waymire and Gupta., 1981) and the space time domain (Radriguez et al., 1986). Although this approach is cluster based so as to model physical structure of rainfall, its application may involve an inconvenient mathematical complexity and a large number of parameters, leading to the several problems in parameter estimation. Another approach to this problem is based on the empirical detection of same regularities in hydrological observations, such as scale invarianceproperties of rainfall (Lovejoy and chertzer, 1985). Models following this approach are based on the assumption of the power law dependence of all statistical moments on the scale of aggregation. That means scaling properties can provide simple relations to link the statistical distribution of the rainfall processes at different temporal scales in the range of which the power law assumptions can be verified (Marani, 2003). Based on the second approach which assumes the power law dependence of all statistical moments on the scale of aggregation, techniques for developing the depth duration frequency model for Oromia Regional State in this study was conducted as follows. Extreme rainfall depth series from fifty five (55) stations were collected and plotted on a logarithmic scale against duration, for several return periods for all stations. The increase of rainfall with duration for various return periods are represented by a line without a slope change at all stations in the study region. For illustration purpose sample plots are given for Addis Ababa station in Figure 1.

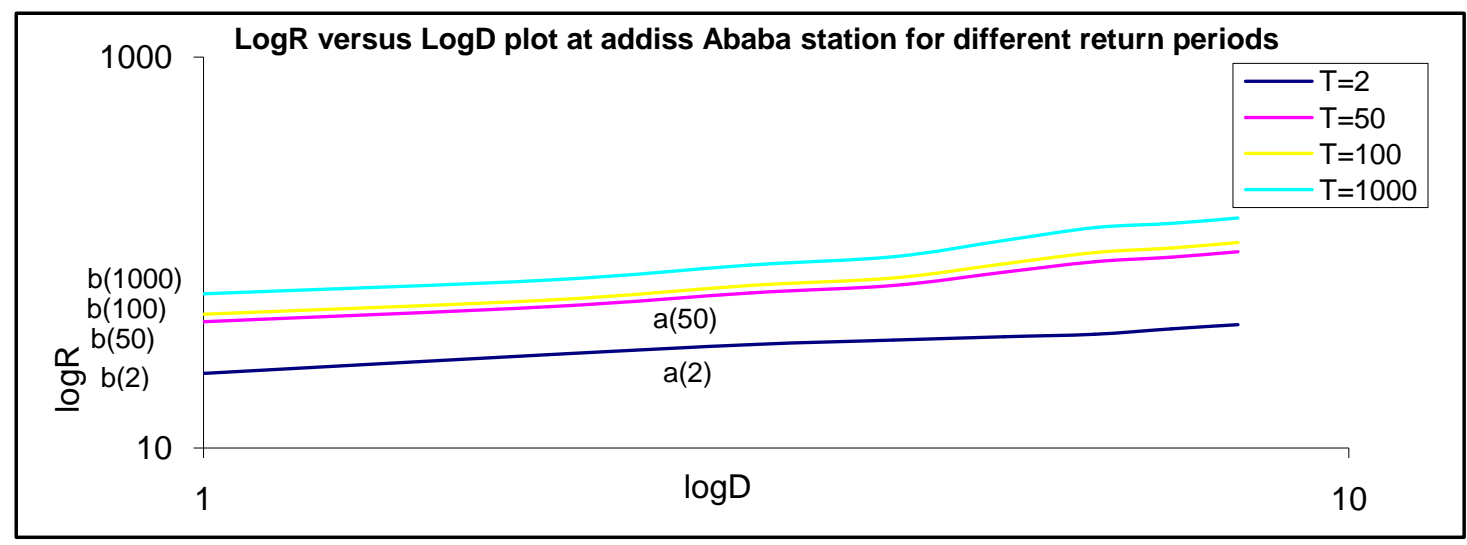

Figure 1: Logarithmic plot of annual maximum rainfall depth versus duration at Addis Ababa station. 


\section{Megersa Tesfaye and Solomon Seyoum}

The log-log plot of the annual maximum rainfall depth series versus the respective durations (Figure 1) revealed that the logarithm of extreme rainfall depth series $(\log R)$ is a linear function of the logarithm of duration $(\log D)$ for
Sci. Technol. Arts Res. J., Oct-Dec 2014, 3(4): 143-151

different return periods. The intercepts and slopes of these linear relationships between $\log R$ and $\log D$ vary with return periods as clearly seen from Figure 1 and Table 1 below.

Table 1: slopes and intercepts at different return periods for $(\log R)$ versus $(\log D)$ plot of Addis Ababa station

\begin{tabular}{ccccc}
\hline $\begin{array}{c}\text { Return } \\
\text { period }\end{array}$ & $\begin{array}{c}\text { Gumbel } \\
\text { Reduced Variate }\end{array}$ & $\begin{array}{c}{[\mathbf{a}(\mathbf{T})]=S l o p e \text { of } \log R \text { vs. } \log \mathbf{D}} \\
\text { at different return periods }\end{array}$ & $\begin{array}{c}{[\mathbf{b}(\mathbf{T}])=\operatorname{Intercept} \text { of } \log R \text { vs. } \log \mathbf{D}} \\
\text { plot at different return periods }\end{array}$ & $\mathbf{R}$ square \\
\hline 2 & 0.366513 & 2.3617 & 24.6 & 0.9984 \\
50 & 3.901939 & 8.3458 & 36.4 & 0.9873 \\
100 & 4.600149 & 9.5276 & 38.73 & 0.9901 \\
1000 & 6.907255 & 13.433 & 46.42 & 0.8974 \\
\hline
\end{tabular}

It is convenient to represent the return period in terms of a reduced variate of the most simple and common distribution function. Therefore, the intercepts and slopes of the $\log R$ and $\log D$ linear equations are fairly explained as a function of the EV1 reduced variate $\left(Y_{T}\right)$. Hence, the rainfall DDF relationships for the study region can be given by:

$$
\log R=b\left(y_{T}\right)+a\left(y_{T}\right) \times \log D
$$

If the fitted distribution is expressed in the form of its cumulative density function, which is given by $F(X)=P(X \leq x)$, which is the probability of nonexceedence; hence

$$
F(X)=P(X \leq x)=1-\frac{1}{T}
$$

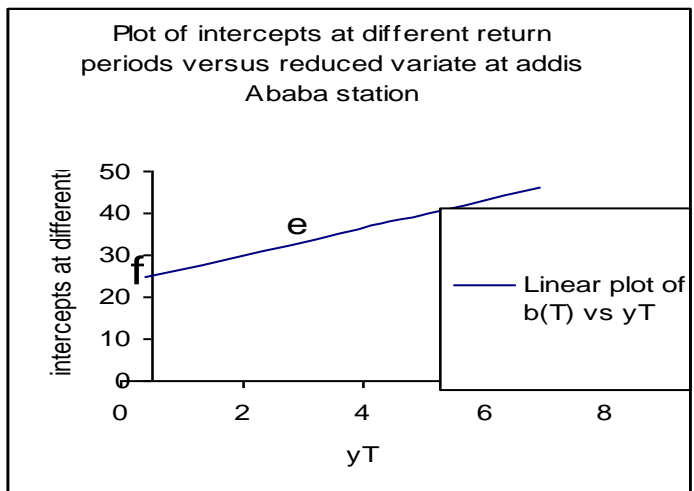

The problem with $F(X)$ is that, when plotted on linear scale, $x$ is a non-linear function of $F(X)$. This is the reason why special graph papers that linearise the relationship are available for many of the more widely used standard frequency distributions. However, the need for special graph papers can be avoided completely if an alternative variable, say $y$ that is a linear function of $X$ is defined as; $x=c+a y$. Where $\mathrm{a}$ and $\mathrm{c}$ are parameters of the distribution of $x$, and $y$ is referred to as the standardized or reduced variate. Following the same principle, a graphical investigation of the intercepts and slopes of log-log plot of rainfall depth series versus duration at all stations were made (figure 2 for illustration) and the result confirmed that both variables are linear functions of the reduced variate.

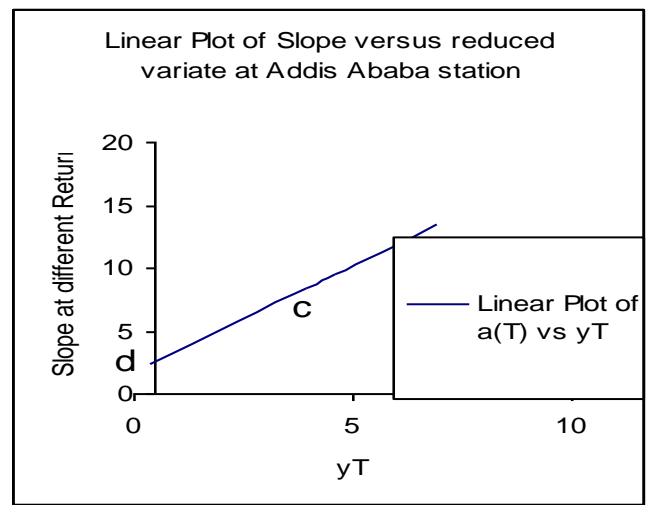

Figure 2: Linear Plot of intercepts and slopes of $\log R$ versus $\log \mathrm{D}$ plot against their reduced variates at Addis Ababa station

When $f, e, d$ and $c$ are parameters of the distribution which controls the slopes and intercepts of the $\log R \log D$ lines and their relation with return periods. Since the intercepts and slopes of the logarithmic plots of extreme rainfall depth versus duration for different recurrence intervals are linearly related to the EV1 reduced variate, $b(T)$ and $a(T)$ are further expressed as:

$$
b(T)=f+e y_{T}
$$

and

$$
a(T)=d+c y_{T}
$$

Hence,

$$
\log (R)=f+e y_{T}+\left[d+c y_{T}\right] \log (D)
$$

From this the final form of the DDF model is given as:

$$
\log (R)=f+e y_{T}+d \log (D)+c y_{T} \log (D)
$$

Where $y_{T}$, is the EV1 reduced variate, $\mathrm{D}$ is duration and $c, d, e, f$, are parameters of the model.
Furthermore, equation (6) could be re-arranged by bringing the return period (EV1 reduced variate) terms together as;

$\log (R)=\{f+d \log (D)\}+\{e+c \log (D)\} y_{T}$

The above equation is equivalent to the logEV1 distribution with location parameter of $\{f+\log (D)\}$ and scale parameter of $\{e+\log (D)\}$. The rainfall DDF relationship can be further simplified as:

$$
\begin{gathered}
\log (R)=\log \left\{\exp (f) D^{d}\right\}+y_{T} \log \left\{\exp (e) D^{c}\right\} \\
\log (R)=\log \left\{\exp (f) D^{d}\right\}+\log \left\{\exp (e) D^{c}\right\}^{y_{T}} \\
R=e^{\log \left[e^{f+e y_{T}} D^{d+c y_{T}}\right]} \\
R=e^{f+e y_{T}} D^{d+c y_{T}} \\
R=e^{f} e^{e y_{T}} D^{d+c y_{T}}
\end{gathered}
$$




$$
R=e^{f}\left(e^{e}\right)^{y T} D^{d+c y_{T}}
$$

From the above equation $e^{f}$ and $e^{e}$ are constants which are equivalent to the natural logarithm of the model parameters $f$ and $e$ Therefore it is possible to assign a constant values $\varepsilon$ and $\varpi$ for $e^{f}$ and $e^{e}$ respectively. Hence the above equation is simplified as:

$$
R=\varepsilon \varpi^{y_{T}} D^{d+c y_{T}}
$$

This is very similar to the Depth Duration Frequency relationship derived from the scaling property of the extreme rainfall depth series (equations 9) and Depth Duration Frequency relationship developed from logEV1distribution(equations 10).

$$
\begin{gathered}
h_{T}(D)=\frac{h_{T}\left(D_{*}\right)}{D_{*}^{\delta+\tau y_{T}}} D^{\delta+y_{T}} \\
h_{T}=\sigma \theta^{y T} D^{\delta+\tau y_{T}}
\end{gathered}
$$

Therefore the DDF model developed has satisfied the requirements of both distribution function and scaling property.

\section{Estimation of Model Parameters}

Recall that the DDF model has the form of

$$
\log R=f+e y_{T}+d \log D+c y_{T} \log D
$$

This is equivalent to the coefficient matrix Formulation of multiple regressions explained as; $y=x b$ where; $y=\left[\begin{array}{l}y_{1} \\ y_{2} \\ y_{3} \\ \cdot \\ \cdot \\ y_{n}\end{array}\right] \quad x=\left[\begin{array}{cccccc}1 & x_{11} & x_{12} & \cdot & \cdot & x_{1 k} \\ 1 & x_{21} & x_{22} & \cdot & \cdot & x_{2 k} \\ 1 & x_{31} & x_{32} & . & \cdot & x_{3 k} \\ \cdot & \cdot & \cdot & \cdot & \cdot & \cdot \\ \cdot & \cdot & \cdot & \cdot & \cdot & \cdot \\ 1 & x_{n 1} & x_{n 2} & x_{n 3} & x_{n 4} & x_{n k}\end{array}\right] \quad b=\left[\begin{array}{l}b_{1} \\ b_{2} \\ b_{3} \\ \cdot \\ \cdot \\ b_{n}\end{array}\right]$

In formulation of matrix regression above the variables $y, x$, and $b$ are often termed as; vector of criterion scores, augmented row score matrix and vector of regression coefficients respectively. Following the same principle, the terms in the DDF model are equivalently expressed in the form of multiple regression matrixes as;

$$
\left[\begin{array}{l}
\log R_{1} \\
\log R_{2} \\
\log R_{3} \\
\cdot \\
\cdot \\
\cdot \log R_{n}
\end{array}\right]=\left[\begin{array}{cccc}
1 & y_{T_{1}} & \log D & y_{T_{1}} \log D \\
1 & y_{T_{2}} & \log D & y_{T_{2}} \log D \\
1 & y_{T_{3}} & \log D & y_{T_{3}} \log D \\
\cdot & \cdot & \cdot & \cdot \\
\cdot & \cdot & \cdot & \cdot \\
1 & y_{T_{n}} & \log D & y_{T_{n}} \log D
\end{array}\right]\left[\begin{array}{l}
f \\
e \\
d \\
c
\end{array}\right]
$$

Accordingly, the four parameters ( $f, e, d$, and $c$ ) of the rainfall DDF model are estimated simultaneously by least square method by solving the above multiple regressions matrixes at each station and the results are found to be acceptable with a minimum coefficient of determination of $70 \%$. Moreover, all the parameters were highly significant

\begin{tabular}{|c|c|c|c|c|c|c|c|c|c|}
\hline Station & $\begin{array}{c}\text { DDF } \\
\text { Parameters }\end{array}$ & Value & $\begin{array}{l}\text { Standard } \\
\text { error }\end{array}$ & $\mathbf{R}^{2}$ & Station & $\begin{array}{c}\text { DDF } \\
\text { Parameters }\end{array}$ & Value & $\begin{array}{l}\text { Standard } \\
\text { error }\end{array}$ & $\mathbf{R}^{2}$ \\
\hline \multirow{4}{*}{ Addis Ababa } & c & 0.00441 & 0.0039 & \multirow{4}{*}{0.93} & \multirow{4}{*}{ Zeway } & c & 0.034225 & 0.0091 & \multirow{4}{*}{0.89} \\
\hline & d & 0.13888 & 0.0053 & & & d & 0.111087 & 0.0118 & \\
\hline & e & 0.19664 & 0.0069 & & & e & 0.276368 & 0.0158 & \\
\hline & $f$ & 3.20121 & 0.0092 & & & $f$ & 3.126924 & 0.0205 & \\
\hline \multirow{4}{*}{ Abomsa } & $\mathrm{c}$ & 0.03671 & 0.0159 & \multirow{4}{*}{0.82} & \multirow{4}{*}{ Yabelo } & $\mathrm{C}$ & -0.00669 & 0.0129 & \multirow{4}{*}{0.90} \\
\hline & $d$ & 0.12125 & 0.0196 & & & $d$ & 0.106321 & 0.0151 & \\
\hline & e & 0.24398 & 0.0277 & & & e & 0.29037 & 0.0225 & \\
\hline & $f$ & 3.23582 & 0.0342 & & & $f$ & 2.90835 & 0.0263 & \\
\hline \multirow{4}{*}{ Agaro } & $\mathrm{C}$ & 0.00297 & 0.018 & \multirow{4}{*}{0.7} & \multirow{4}{*}{ Wolliso } & $\mathrm{C}$ & -0.03191 & 0.0098 & \multirow{4}{*}{0.82} \\
\hline & $d$ & 0.15421 & 0.023 & & & d & 0.218827 & 0.0125 & \\
\hline & e & 0.25683 & 0.031 & & & e & 0.167653 & 0.0171 & \\
\hline & $f$ & 3.02518 & 0.040 & & & $f$ & 3.215475 & 0.0218 & \\
\hline \multirow{4}{*}{ Ambo } & c & -0.00635 & 0.007 & \multirow{4}{*}{0.93} & \multirow{4}{*}{ Sinana } & c & -0.01529 & 0.0132 & \multirow{4}{*}{0.90} \\
\hline & d & 0.22274 & 0.009 & & & d & 0.268379 & 0.0165 & \\
\hline & e & 0.24570 & 0.013 & & & e & 0.320128 & 0.0231 & \\
\hline & $f$ & 2.71913 & 0.017 & & & $f$ & 2.94052 & 0.0288 & \\
\hline \multirow{4}{*}{ arjo } & c & 0.03447 & 0.014 & \multirow{4}{*}{0.88} & \multirow{4}{*}{ Shambu } & c & 0.007278 & 0.0055 & \multirow{4}{*}{0.95} \\
\hline & d & 0.20303 & 0.016 & & & d & 0.190327 & 0.0071 & \\
\hline & e & 0.17811 & 0.024 & & & e & 0.206303 & 0.0097 & \\
\hline & f & 3.32462 & 0.029 & & & $f$ & 3.285899 & 0.0124 & \\
\hline \multirow{4}{*}{ Arsi-Adele } & c & 0.00953 & 0.0071 & \multirow{4}{*}{0.95} & \multirow{4}{*}{ Sokoru } & c & -0.01198 & 0.0043 & \multirow{4}{*}{0.94} \\
\hline & d & 0.15670 & 0.0087 & & & d & 0.132242 & 0.0056 & \\
\hline & e & 0.23165 & 0.0123 & & & e & 0.201067 & 0.0075 & \\
\hline & f & 2.94271 & 0.0152 & & & f & 3.329610 & 0.0096 & \\
\hline \multirow{4}{*}{ Arsi-Robe } & c & 0.00858 & 0.0066 & & & c & 0.010135 & 0.0097 & \\
\hline & $d$ & 0.10039 & 0.0085 & & & d & 0.082536 & 0.0116 & \\
\hline & e & 0.28846 & 0.0115 & 0.94 & Negele & $\mathrm{e}$ & 0.165095 & 0.0168 & 0.86 \\
\hline & $f$ & 3.23715 & 0.0148 & & & f & 3.294786 & 0.0202 & \\
\hline & c & -0.01936 & 0.0173 & & & c & 0.029358 & 0.0070 & \\
\hline & $d$ & 0.19465 & 0.0208 & & & d & 0.205373 & 0.0088 & \\
\hline Asossa & e & 0.22563 & 0.0302 & 0.19 & Nedjo & e & 0.182884 & 0.0122 & 0.95 \\
\hline & f & 3.22570 & 0.0362 & & & f & 3.234249 & 0.0154 & \\
\hline & $\mathrm{c}$ & 0.01258 & 0.0121 & & & $\mathrm{c}$ & 0.009295 & 0.0074 & \\
\hline & d & 0.07894 & 0.0162 & & & d & 0.153634 & 0.0092 & \\
\hline Awasa & $\mathrm{e}$ & 0.25724 & 0.0211 & 0.12 & Adama & e & 0.241219 & 0.0128 & 0.94 \\
\hline & f & 3.4369 & 0.0283 & & & f & 3.165781 & 0.0160 & \\
\hline Avira & c & -0.00358 & 0.0078 & 092 & & c & -0.02319 & 0.0186 & 087 \\
\hline Aylra & d & 0.20576 & 0.0100 & 0.92 & Mroyale & d & 0.172119 & 0.0212 & 0.87 \\
\hline
\end{tabular}
in the sense that they have very small standard errors. The estimated values of the model parameters along with their standard errors of estimates at all stations are shown in table 2.

Table 2: Estimated values of the model parameters with their standard errors and efficiency of estimation 


\begin{tabular}{|c|c|c|c|c|c|c|c|c|c|}
\hline & $\begin{array}{l}e \\
f\end{array}$ & $\begin{array}{l}0.22930 \\
3.39847\end{array}$ & $\begin{array}{l}0.0136 \\
0.0174\end{array}$ & & & $\begin{array}{l}e \\
f\end{array}$ & $\begin{array}{l}0.235958 \\
3.350277\end{array}$ & $\begin{array}{l}0.0264 \\
0.0301\end{array}$ & \\
\hline \multirow{4}{*}{ Bale Robe } & $C$ & 0.01163 & 0.0093 & \multirow{4}{*}{0.87} & \multirow{4}{*}{ Mirab-Abaya } & C & -0.00568 & 0.0073 & \multirow{4}{*}{0.93} \\
\hline & $d$ & 0.12925 & 0.0118 & & & d & 0.170731 & 0.0094 & \\
\hline & e & 0.20139 & 0.0163 & & & e & 0.278438 & 0.0128 & \\
\hline & $f$ & 3.10046 & 0.0205 & & & $f$ & 3.161785 & 0.0164 & \\
\hline \multirow{4}{*}{ Begelle } & $C$ & 0.00641 & 0.0043 & \multirow{4}{*}{0.94} & \multirow{4}{*}{ Miesso } & $\mathrm{C}$ & 0.025544 & 0.0067 & \multirow{4}{*}{0.96} \\
\hline & $d$ & 0.15341 & 0.0056 & & & $\mathrm{~d}$ & 0.049318 & 0.0083 & \\
\hline & e & 0.15971 & 0.0078 & & & e & 0.28657 & 0.0117 & \\
\hline & $f$ & 3.29199 & 0.0098 & & & $f$ & 3.27315 & 0.0144 & \\
\hline \multirow{4}{*}{ Bekoji } & C & -0.0098 & 0.0063 & & & C & -0.02547 & 0.0067 & \\
\hline & $d$ & 0.11948 & 0.0082 & & & $d$ & 0.148368 & 0.0086 & \\
\hline & e & 0.27443 & 0.0110 & 0.92 & Metehara & e & 0.261162 & 0.0116 & 0.91 \\
\hline & $f$ & 3.32261 & 0.0143 & & & $f$ & 3.154645 & 0.0150 & \\
\hline & $C$ & 0.00341 & 0.0127 & & & C & 0.025620 & 0.0204 & \\
\hline & $d$ & 0.12946 & 0.0163 & & & $d$ & 0.142514 & 0.0239 & \\
\hline Bishoftu & $\mathrm{e}$ & 0.27126 & 0.0222 & 0.81 & Mega & e & 0.332655 & 0.0356 & 0.81 \\
\hline & $f$ & 3.13138 & 0.0284 & & & $f$ & 2.962074 & 0.0417 & \\
\hline & C & 0.03467 & 0.0127 & & & C & 0.007216 & 0.0080 & \\
\hline & $d$ & 0.19958 & 0.0152 & & & $d$ & 0.121039 & 0.0106 & \\
\hline Ciro & $\mathrm{e}$ & 0.27358 & 0.0221 & 0.93 & Kulumsa & e & 0.285903 & 0.0139 & 0.86 \\
\hline & $f$ & 3.24190 & 0.0265 & & & $f$ & 3.100605 & 0.0185 & \\
\hline & $C$ & 0.01159 & 0.0070 & & & c & 0.00904 & 0.0134 & \\
\hline & $d$ & 0.14388 & 0.0092 & & & $d$ & 0.103977 & 0.0175 & \\
\hline Debre Marıkos & e & 0.29374 & 0.0123 & 0.93 & Konso & e & 0.215509 & 0.0234 & 0.15 \\
\hline & $f$ & 3.11623 & 0.0161 & & & $f$ & 3.238733 & 0.0304 & \\
\hline & $C$ & 0.00783 & 0.0074 & & & C & -0.01668 & -0.0068 & \\
\hline Rehre Rirehan & $d$ & 0.18421 & 0.0097 & & & $d$ & 0.144921 & 0.0088 & \\
\hline Debre Birenan & e & 0.24391 & 0.0129 & 0.90 & Kachise & $\mathrm{e}$ & 0.172105 & 0.0119 & 0.85 \\
\hline & $f$ & 2.91982 & 0.0169 & & & $f$ & 3.294603 & 0.0154 & \\
\hline & C & 0.01774 & 0.0109 & & & C & -0.00598 & 0.0037 & \\
\hline & $d$ & 0.14585 & 0.0135 & & & $d$ & 0.151466 & 0.0049 & \\
\hline Deder & $\mathrm{e}$ & 0.23219 & 0.0191 & 0.89 & Jimma & e & 0.175367 & 0.0065 & 0.94 \\
\hline & $f$ & 3.23666 & 0.0236 & & & $f$ & 3.307588 & 0.0086 & \\
\hline & $C$ & -0.00251 & 0.0049 & & & C & -0.00709 & 0.0077 & \\
\hline Degehahour & $d$ & 0.08694 & 0.0062 & 096 & Humuru & $d$ & 0.177943 & 0.0096 & 0.93 \\
\hline Degenabour & e & 0.25923 & 0.0086 & 0.96 & & e & 0.233927 & 0.0134 & \\
\hline & $f$ & 3.26038 & 0.0109 & & & $f$ & 3.274882 & 0.0167 & \\
\hline & $C$ & 0.00085 & 0.0081 & & & C & -0.00335 & 0.0124 & \\
\hline Dembidolo & $d$ & 0.12711 & 0.0104 & & & $d$ & 0.106769 & 0.0151 & \\
\hline Demididolo & e & 0.16676 & 0.0142 & 0.83 & Hurso & e & 0.160340 & 0.0251 & 0.74 \\
\hline & $f$ & 3.24809 & 0.0181 & & & $f$ & 3.327964 & 0.0263 & \\
\hline & $C$ & 0.00317 & 0.0149 & & & C & 0.003796 & 0.0143 & \\
\hline & $d$ & 0.13792 & 0.0186 & & & $d$ & 0.153427 & 0.0167 & \\
\hline Didessa & e & 0.31072 & 0.0260 & 0.84 & Hunte & e & 0.207049 & 0.0249 & 0.86 \\
\hline & $f$ & 3.19936 & 0.0324 & & & $f$ & 3.094403 & 0.0291 & \\
\hline & $C$ & 0.00969 & 0.0094 & & & C & -0.0291 & 0.0050 & \\
\hline Dilla & $d$ & 0.11309 & 0.0120 & 088 & & $d$ & 0.135763 & 0.0050 & \\
\hline DIlla & e & 0.24877 & 0.0163 & 0.88 & Haramaya & $\mathrm{e}$ & 0.218810 & 0.0065 & 0.93 \\
\hline & $f$ & 3.41112 & 0.0208 & & & $f$ & 3.371481 & 0.0088 & \\
\hline & C & -0.01799 & 0.0048 & & & C & 0.002847 & 0.0090 & \\
\hline & $d$ & 0.000084 & 0.0063 & & & $d$ & 0.184492 & 0.0114 & \\
\hline Diredawa & e & 0.218216 & 0.0083 & 0.89 & Hagere IMarıam & e & 0.221043 & 0.0157 & 0.90 \\
\hline & $f$ & 3.147466 & 0.0113 & & & $\mathrm{f}$ & 3.046226 & 0.0200 & \\
\hline & $C$ & 0.013314 & 0.0074 & & & C & 0.000599 & 0.0032 & \\
\hline liaii & $d$ & 0.169308 & 0.0091 & 0,03 & Goro & $d$ & 0.097213 & 0.0043 & 005 \\
\hline IJajı & e & 0.163449 & 0.0128 & 0.93 & Gore & e & 0.206285 & 0.0056 & 0.95 \\
\hline & $f$ & 3.109883 & 0.0159 & & & $f$ & 3.376289 & 0.0075 & \\
\hline & $C$ & -0.00608 & 0.0071 & & & $C$ & -0.03319 & 0.0083 & \\
\hline Ficho & $d$ & 0.160206 & 0.0094 & 085 & & $d$ & 0.189448 & 0.0108 & \\
\hline FIche & $\mathrm{e}$ & 0.208717 & 0.0125 & 0.85 & Goba & e & 0.282183 & 0.0145 & 0.89 \\
\hline & $f$ & 3.262654 & 0.0164 & & & $f$ & 2.915577 & 0.0188 & \\
\hline & $C$ & -0.00993 & 0.0059 & & & C & 0.053223 & 0.0073 & \\
\hline & $d$ & 0.059577 & 0.0076 & & & $d$ & 0.107668 & 0.0093 & \\
\hline Garba-Guracha & $\mathrm{e}$ & 0.10992 & 0.0104 & 0.70 & Ginnir & e & 0.224670 & 0.0127 & 0.94 \\
\hline & $f$ & 3.365064 & 0.0133 & & & $f$ & 3.137756 & 0.0162 & \\
\hline & $C$ & -0.00786 & 0.0127 & & & C & -0.02230 & 0.0233 & \\
\hline Golomco & $d$ & 0.107015 & 0.0155 & 080 & & d & 0.213197 & 0.0265 & \\
\hline Gelemso & e & 0.212733 & 0.0221 & 0.80 & Gimbi & e & 0.260236 & 0.0406 & 0.80 \\
\hline & $f$ & 3.23276 & 0.0270 & & & f & 3.353416 & 0.0462 & \\
\hline $\mathrm{Go}_{0}$ & C & 0.011289 & 0.0099 & 080 & Gewane & $\mathrm{e}$ & 0.246279 & 0.0172 & 88 \\
\hline vane & $d$ & 0.086597 & 0.0123 & 0.88 & & $f$ & 3.356674 & 0.0215 & 0.88 \\
\hline
\end{tabular}


Megersa Tesfaye and Solomon Seyoum

\section{Mapping of the Model Parameters}

Only sets of point parameters were estimated from the rainfall record of point rain gauges. However we need the model parameters at any point, as the network of hourly rainfall recording rain gauges in the study area has low density. Therefore, Maps of the parameters on every
Sci. Technol. Arts Res. J., Oct-Dec 2014, 3(4): 143-151

$1 \mathrm{~km}$ grid were required, enabling the estimation of design rainfall for any location in the study area. Since no useful relationships were found between the four model parameters and elevation (Figure 3), all four parameters were interpolated to a $1 \mathrm{~km}$ grid size by ordinary kriging (a weighted mean with weight dependent on distance).

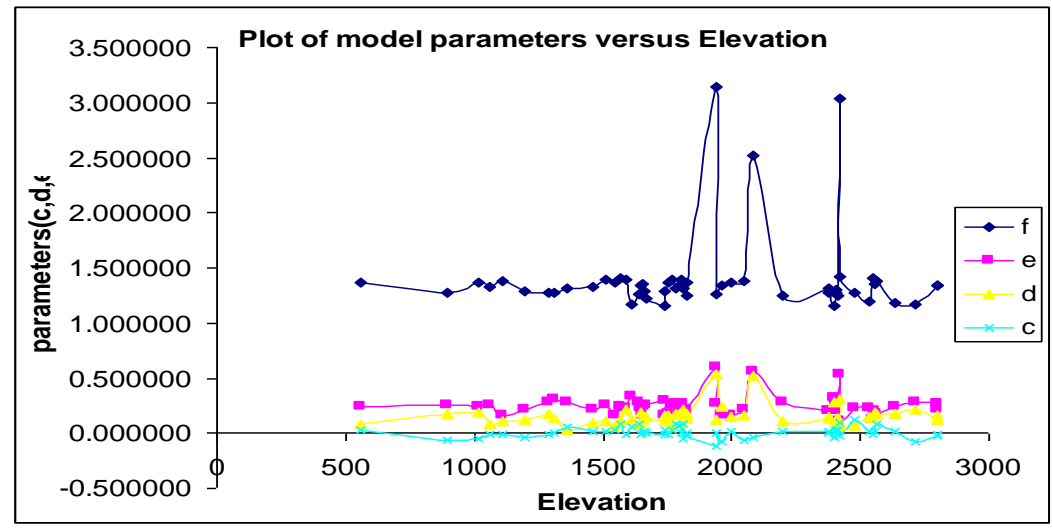

Figure 3: Systematic diagram showing the relation of DDF parameters against elevation

a. Interpolated c parameter

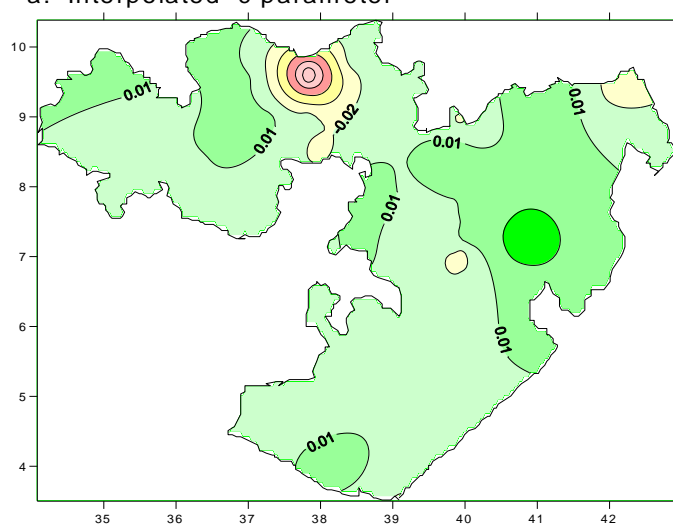

c. Interpolated e parameter

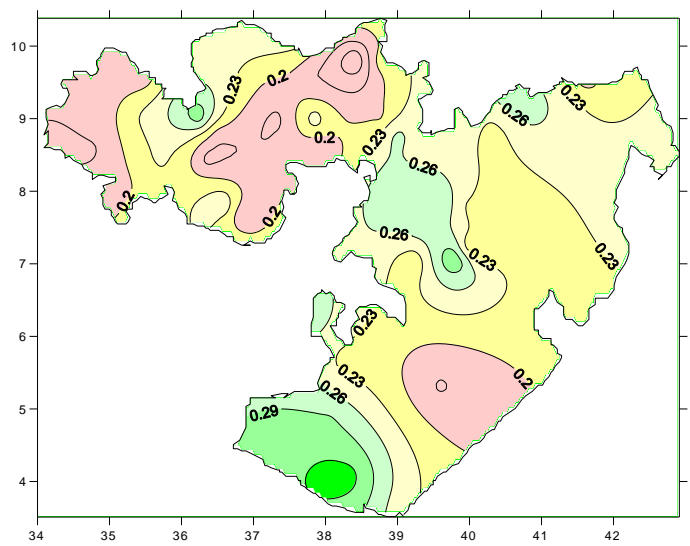

b. Interpolated d parameter
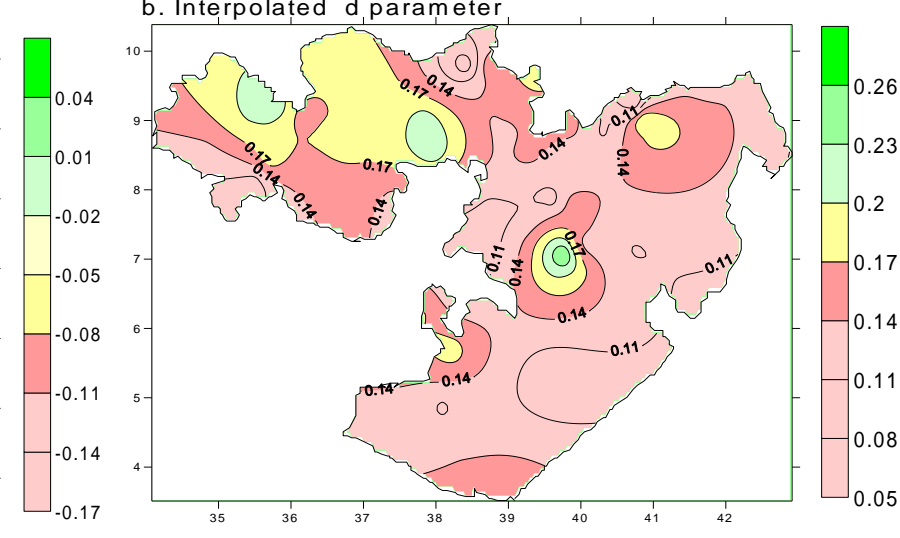

d. Interpolated f parameter
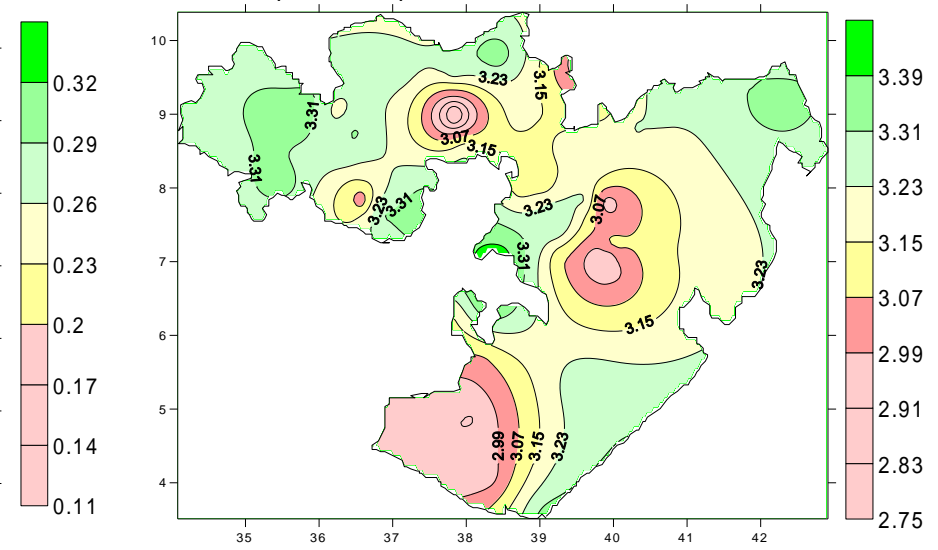

Figure 4: Map of the DDF model parameters

\section{Model Efficiency Test}

The quantile estimate by DDF model for different return periods of rainfall at different durations were checked against estimates provided by fitting logEV1 distribution. It is found that the developed DDF model has satisfactorily reproduced the rainfall depth duration frequency relationship at all stations considered for this study in the study region (Figure 5).
Estimates found from the scaling DDF model were also compared with observed quantiles of extreme rainfall depth. The DDF model developed for a region satisfactorily reproduces the observed extreme rainfall depth series at all stations in the study region (Figure 6 for illustration). 

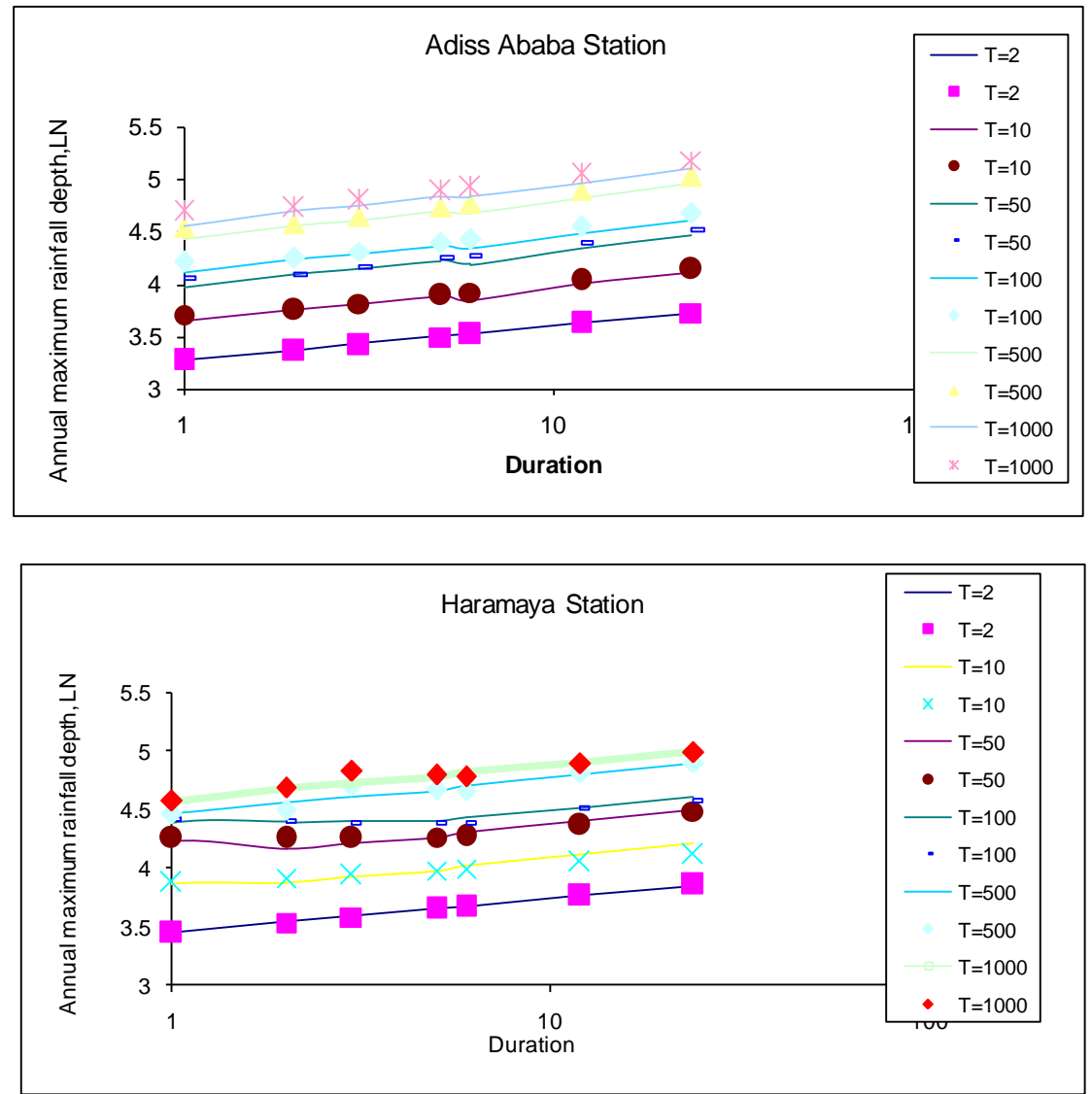

Figure 5: Comparison of the rainfall depth duration frequency relationships estimated by logEV1 (points) and DDF Model (lines)
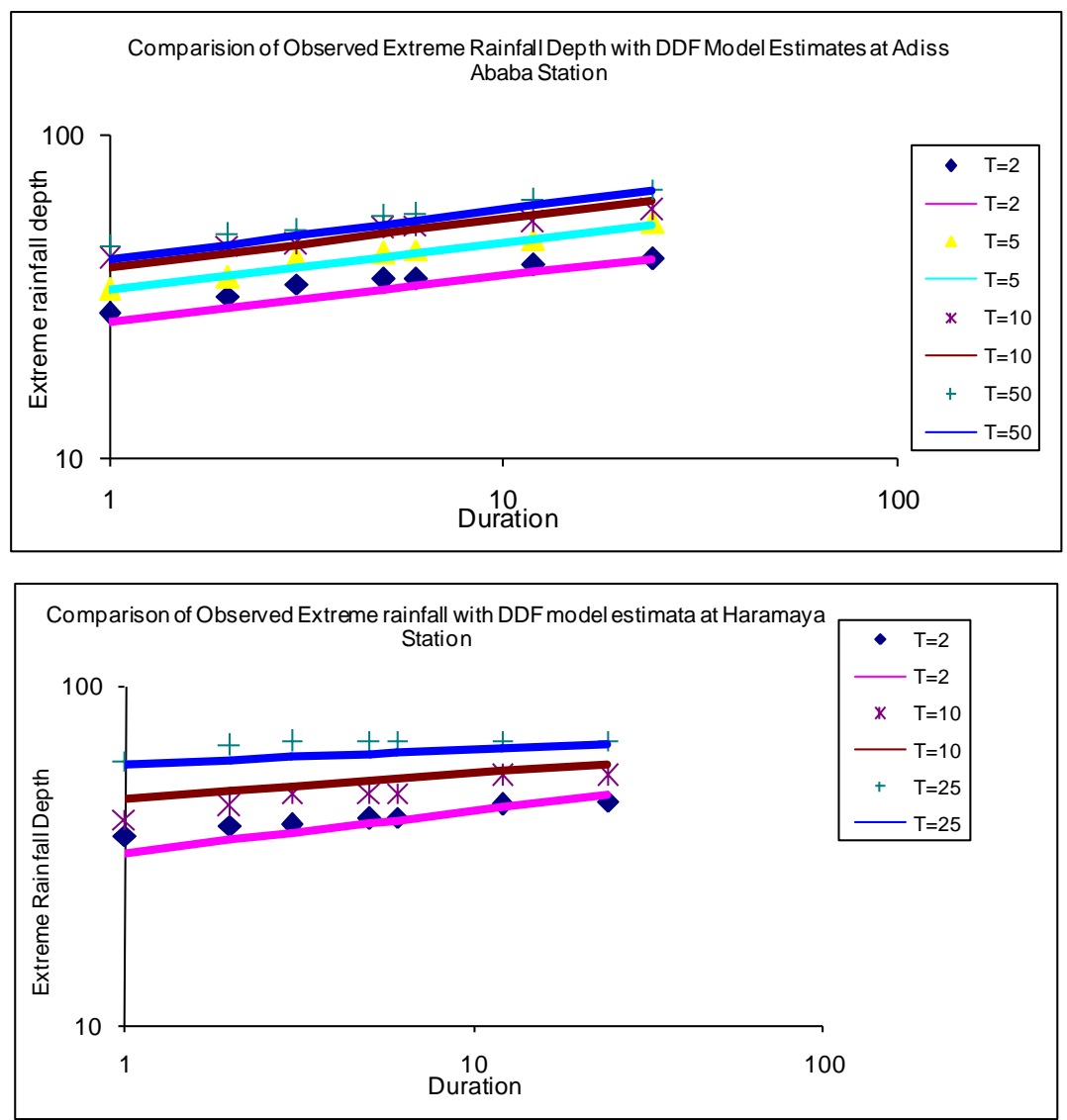

Figure 6: Comparison of Observed extreme rainfall depth series (points) and DDF model estimates (lines). 


\section{Megersa Tesfaye and Solomon Seyoum}

Moreover, the quantile estimates of the DDF model was also compared with the IDF estimates previous developed for the region (Chali Edessa and Semu
Sci. Technol. Arts Res. J., Oct-Dec 2014, 3(4): 143-151

Ayalew, 2007) and the agreement is surprisingly good at all stations (Table 3 for illustration).

Table 3: Comparison of quantiles estimated by DDF mode (bold) and previously developed IDF relationship at Haramaya station

\begin{tabular}{ccccccccccc}
\hline \multirow{2}{*}{ Duration } & \multicolumn{2}{c}{ T=2 } & \multicolumn{2}{c}{ T=5 } & \multicolumn{2}{c}{ T=10 } & \multicolumn{2}{c}{ T=50 } & \multicolumn{2}{c}{ T=100 } \\
\cline { 2 - 11 } & IDF & DDF & IDF & DDF & IDF & DDF & IDF & DDF & IDF & DDF \\
\hline 0.5 & 23.44 & 28.93 & 32.68 & 34.90 & 38.79 & 39.91 & 52.25 & 53.41 & 57.94 & 60.28 \\
1 & 26.97 & 31.55 & 38.82 & 40.43 & 46.67 & 47.65 & 63.95 & 68.39 & 71.25 & 79.68 \\
2 & 28.93 & 34.41 & 42.01 & 42.04 & 50.67 & 48.02 & 69.73 & 64.13 & 77.79 & 72.33 \\
3 & 30.30 & 36.20 & 44.53 & 44.39 & 53.96 & 50.69 & 74.69 & 67.65 & 83.46 & 76.29 \\
5 & 31.30 & 38.59 & 46 & 46.89 & 55.73 & 53.35 & 77.15 & 70.88 & 86.21 & 79.92 \\
6 & 32.41 & 39.48 & 47.19 & 48.72 & 56.97 & 55.60 & 78.52 & 74.14 & 87.63 & 83.58 \\
12 & 34.47 & 43.06 & 49.37 & 53.47 & 59.23 & 60.99 & 80.95 & 81.25 & 90.13 & 91.57 \\
24 & 35.75 & 46.96 & 51.45 & 58.69 & 61.85 & 66.91 & 84.73 & 89.06 & 94.4 & 100.33 \\
\hline
\end{tabular}

Farther more, quantile estimates of DDF model and IDF relationship at different return periods was also compared with observed extreme rainfall depth (Figure 7 for illustration). It was shown that despite of its mathematical sophistication; involvement of too many parameters, and sequential steps, the conventional approach of characterizing the random nature of observed rainfall was not show better estimates than the DDF model. Moreover traditional methods to derive intensity duration relationships are not accurate and reliable since they depend on assumptions such as distribution selection for each duration, they require a large number of parameters, and the selection of the distributions does not base on any physical principles. Many criticisms have been also made on such approach for being inadequate for cases when sample size is small (Pendy et al., 1998).
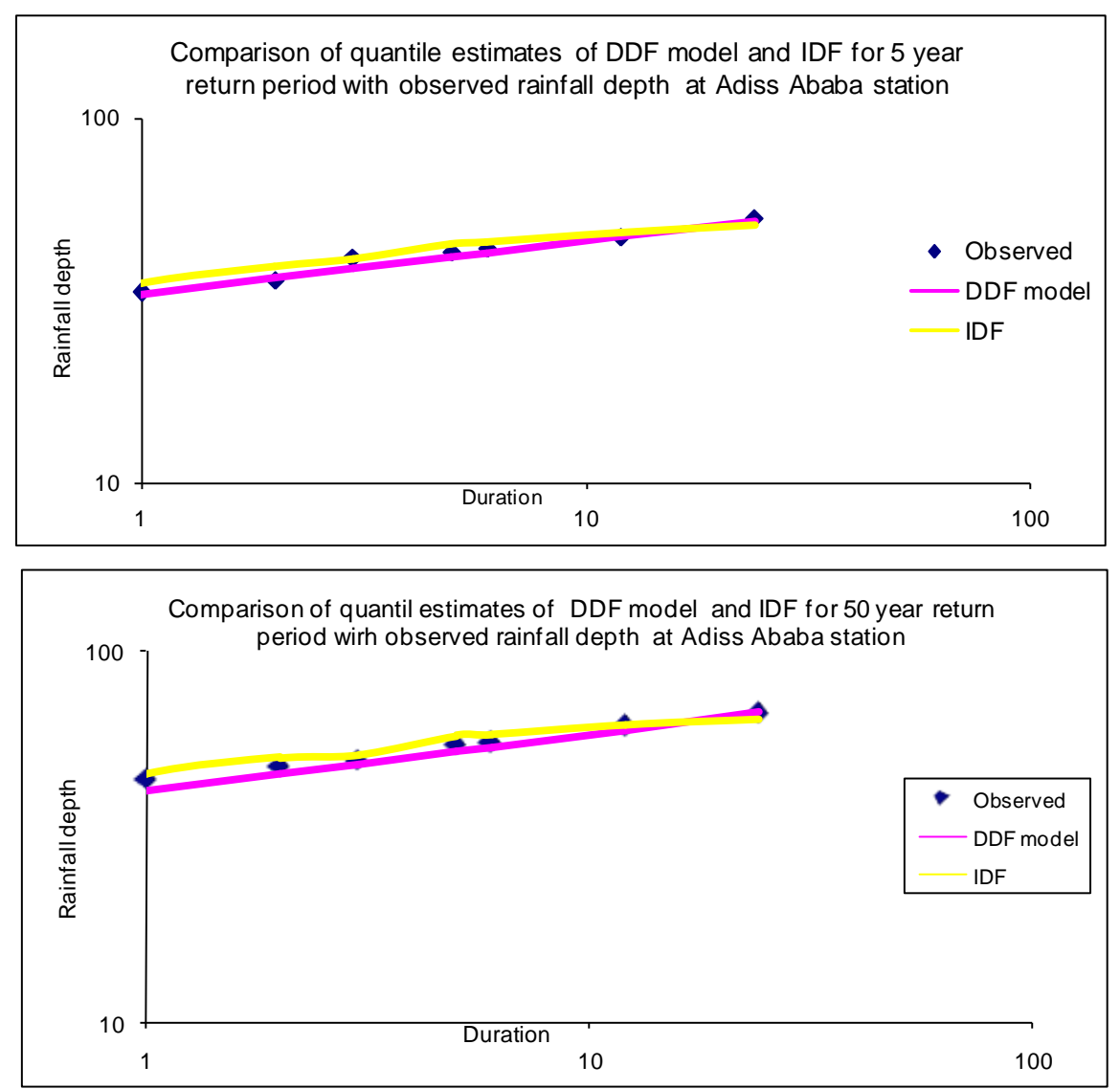

Figure 7: Comparison of Observed extreme rainfall depth series (points) with DDF model estimates and IDF estimates at 5 and 50 year return periods (lines) respectively

\section{Application of the Model}

The form of the model considered as in equation (6), with four parameters (c, e, $d$, and $f)$ is:

$$
\log (R)=f+e Y_{T}+d \log (D)+c Y_{T} \log (D)
$$

As already described, the station value of these four parameters required by the model was available at $1 \mathrm{~km}$ grid. Therefore at each grid points the DDF model could then be used to derive the return period rainfalls for any duration in the study region. 


\section{Megersa Tesfaye and Solomon Seyoum}

Therefore, two tasks were performed:

1. Given duration $D$ and return period $T$, estimate $R(T, D)$, the design rainfall depth that would be exceeded on average once in $T$ years.
Sci. Technol. Arts Res. J., Oct-Dec 2014, 3(4): 143-151

2. Given duration $D$ and $R(T, D)$, estimate the return period, the frequency of occurrence of the rainfall depth.

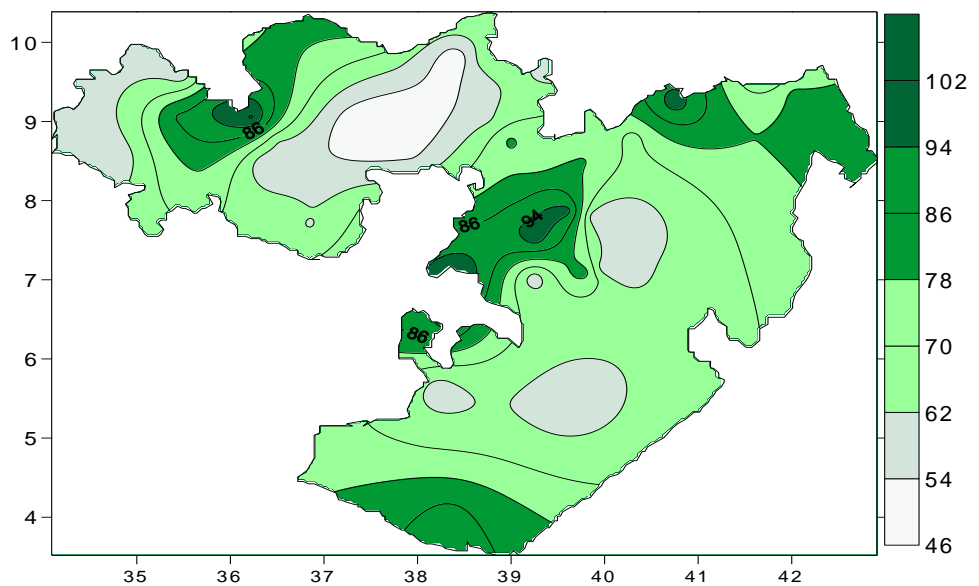

Figure 8: Map of Rainfall Depth, Return Period 100 years, Duration $1 \mathrm{hr}$

\section{CONCLUSSIONS}

The study demonstrated the development and application of the model that robustly explains the rainfall depth, duration and frequency relationships in Oromia regional state. Based on the assumption of the power law dependence of all statistical moments on the scale of aggregation, i.e. scaling properties of extreme rainfall depth series which can provide simple relationships to link the statistical distribution of the rainfall processes at different temporal scales, Depth Duration Frequency model was developed which allows for the estimation of point design rainfall frequencies for a range of durations for any location in the study region. The model consisted of four parameters and it is fitted to the series of annual maxima and these parameters were determined by least squares method. An attempt was made to relate this parameter to the environmental and topographic variables. However, no useful relationships were found between the four parameters and the environmental, topographic and physiographic variables such as elevation. The graphical and numerical comparisons of the performance of the DDF model were made against the sample and quantile estimates of distribution functions, observed rainfall depth and also against empirical IDF quantile estimates. The comparison result confirmed that the DDF model has provided consistent quantile estimates with that of the logEV1 and superior estimates than empirical IDF estimates. It is concluded that statistical analysis and empirical detection of some regularities in hydrological observations, such as scale invariance properties of rainfall can provide simple relationships to link the statistical distribution of the rainfall processes at different temporal scales and enables to develop a model that robustly best explains the design rainfall depth.

\section{REFERENCES}

Adamocuski, K. (1997). Regional analysis of annual maximum and partial duration flood data by non parametric and L-moment methods. Journal of Hydrology 229(3-4): 219-231.

Ahmad, M.I., Sinclair, C.D. and werrity (1988). A log- logistic flood frequency analysis. Journal of Hydrology 98: 215224.
Burlando and Rosso (1996). Scaling and multi-scaling models of depth duration frequency curves for storm precipitation. Journal of Hydrology 187: 45-65.

Chen, C.L (1983). Rainfall intensity duration frequency formulas. Journal of Hydraulic Engineering 109(12): 16031621.

Chow, V.T., Maidment, D.R and Mays, L.W. (1988). Applied Hydrology, McGraw-Hill, 1988.

Fizgegland, D.L. (2007). Estimation of point rainfall frequencies. Irish meteorological service, Technical Note 61.

Gupta, A.K. and Waymire, E. (1991). Multi-scaling properties of special rainfall and river flow distributions. Journal of Geophysical Research 95(D3):1999-2009.

Gupta, V.K. and Waymire, E.C. (1990), A statistical Analysis of Mesoscale rainfall as a Random Cascade. Journal of Applied Meteorology 32: 251-267.

Hosking, J.R.M. (1990). L-moments: analysis and estimation of distributions using linear combinations of order statistics. Journal of Royal Statistical Society Series 52(1): 105-124.

Institute of hydrology (1999). Flood studies hand book. Institute of hydrology, Wallingford.

Jenkinson, A.F. (1955). Frequency Distribution of Maximum Values. Quarterly Journal of the Royal Meteorological Society 81: 158-171.

Koutsoyiannis, D., Foufoula-Georgiu, E., (1993), A scaling model of storm hyetograph. Water Resource 29(7): 23452361.

Koutsoyiannis, D., Manetas. (1998). A mathematical frame work for studying rainfall intensity duration frequency relationship. Journal of Hydrology 206: 118-135.

Willems(2001), Compound intensity duration frequency relationship of extreme precipitation for two seasons and two storm types. Journal of Hydrology 233(1-4): 189-205

Willems, P. (2001). Compound Intensity/Duration/Frequency Relationships of Extreme precipitation for two Seasons and two Storm types. Journal of Hydrology 233: 189-205. 